\title{
Stress and Resources in Women Attending an Inpatient Prevention/Rehabilitation Measure for Parents: Secondary Analysis of Quality Assurance Data
}

\author{
Matthias Lukasczik ${ }^{1}$, Christian Gerlich ${ }^{1}$, Michael Schuler ${ }^{1}$, Silke Neuderth ${ }^{1}$, \\ Gabriele Dlugosch², Hermann Faller' \\ ${ }^{1}$ University of Würzburg, Department of Medical Psychology, Medical Sociology and Rehabilitation Sciences, \\ Würzburg, Germany \\ ${ }^{2}$ University of Landau, Empirical Educational Research Center, Landau, Germany \\ Email: matthias.lukasczik@uni-wuerzburg.de
}

Received 30 January 2015; accepted 3 April 2015; published 7 April 2015

Copyright (C) 2015 by authors and Scientific Research Publishing Inc.

This work is licensed under the Creative Commons Attribution International License (CC BY). http://creativecommons.org/licenses/by/4.0/

c) (7) Open Access

\begin{abstract}
Questionnaire data from two projects on the development of quality assurance instruments for an inpatient rehabilitation/prevention program for parents were used for a secondary analysis. In this analysis, the associations of gains in a psychosocial resource (parenting self-efficacy) and two types of stressors experienced by mothers at the start of treatment (parenting hassles, depressive symptoms) with general life satisfaction and satisfaction with health at the end of treatment were explored. Structural equation modeling was applied to data from $\mathrm{N}=1724$ female patients. Potential resource-stressor interactions were tested using the Latent Moderated Structural Equations approach. Results showed that parenting hassles were negatively associated with general life satisfaction and satisfaction with health while self-efficacy gains were weakly positively correlated with both variables. No interaction of parenting hassles and self-efficacy gains was found. Depressive symptoms were negatively associated with both satisfaction measures. In these models, selfefficacy gains were not substantially correlated with life satisfaction, but showed a small association with satisfaction with health. There was no significant interaction of depressive symptoms and self-efficacy gains. The findings imply that interventions for distressed mothers-as exemplarily illustrated by this inpatient setting-should focus on identifying and reducing initial stressors as these may continue to impair mothers' subjective health despite gains in parenting-related resources.
\end{abstract}




\section{Keywords}

\section{Depression, Self-Efficacy, Resource, Parenting Stress, Mothers}

\section{Introduction}

Mothers and fathers have to handle a variety of demands they may experience as stressful. Besides role conflicts [1], socio-economic difficulties (e.g., among single parents [2]) or a child's chronic or life-threatening disease [3], everyday hassles related to childrearing such as annoying or noncompliant child behaviors [4] [5] constitute a prevalent source of parental strain. There is evidence that mothers are more negatively affected by parenting-related hassles [6] and demands resulting from household and family work [7] [8] than fathers. Moreover, parenting or caretaking hassles constitute a more pronounced risk factor for mental health problems such as depression in women [9]-[12].

Subgroups of mothers (and fathers) may be particularly affected by health problems that result from the interplay of stressors such as those mentioned above. For instance, two German studies have shown that parenting hassles as well as depressive symptoms are prevalent stressors in women seeking preventive or rehabilitative treatment [10] [13]. Another German survey has estimated that there is a need for preventive or rehabilitative interventions in up to $20 \%$ of fathers and mothers [14]. Thus, clinical or preventive approaches adapted to the specific needs and life context of distressed mothers/fathers as well as their respective medical condition may be necessary. Existing interventions vary in terms of setting, scope, and empirical validation.

\subsection{Study Setting}

A specific type of intervention (which is the setting of the analysis presented in this paper) has been realized in Germany in the form of inpatient prevention and rehabilitation (PRP) programs for parents (see [15] for an overview on the German rehabilitation system). They are offered as a 3-week inpatient treatment program in specialized rehabilitation centers that focus on one or several core indications (e.g., psychosomatics, and metabolic diseases). Originally, the programs addressed only mothers; from 2002 on, fathers might also attend a PRP program. Some clinics also offer combined mother-/father-child measures. Since PRP programs are provided by the statutory health insurance as a health care benefit, patients applying for it have to undergo a socio-medical evaluation by health insurance medical staff regarding eligibility for the program (i.e., (chronic) somatic, functional and/or psychosocial health impairments, contextual factors relevant to health associated with childcare such as a troubled/dysfunctional mother-child relationship, and parenting-specific stressors). Patients are then referred to a PRP clinic depending on their primary medical diagnosis or health problem.

Besides preventive or rehabilitative treatment of the patient's specific medical condition, PRP programs also comprise resource-oriented individual- and/or group-based psychosocial components (e.g., parent trainings, and counseling) that focus on the promotion of functional parenting behavior and parenting self-efficacy. The latter is an important indicator of parental competence [16] and has been shown to improve in parent trainings [17] [20]. There is no standardized PRP regimen in terms of a uniform program implemented in all clinics. However, all institutions offering PRP have to adhere to the joint profiles of requirements agreed upon by the German federal health insurance funds and care providers [21] in terms of a common framework.

Only a small body of research has dealt with PRP in recent years. In particular, little is known in this setting about the interplay of stressors and resources as major determinants of well-being and health of PRP patients. Therefore, data collected in the context of PRP quality assurance (see below) were used for a secondary analysis with the goal to explore how prevalent stressors and parenting-related resources are interrelated and how they are associated with maternal satisfaction at the end of treatment. Referring to the variables identified as relevant to this setting, parenting hassles and depressive symptoms were operationalized as distress indicators. Parenting self-efficacy was operationalized as a resource indicator (see below).

\subsection{Research Questions}

The following explorative research questions were addressed: 
1) Are gains in parenting self-efficacy (PSE) in the course of a PRP program positively associated with general life satisfaction and satisfaction with health, respectively, at the end of the program?

2) Are these associations moderated by stressors experienced at the start of treatment (everyday stressors related to parenting and childcare; depressive symptoms)?

As a guiding conceptual frame, conservation of resources (COR) theory [22] was used as it makes assumptions on the relation of stressors and psychosocial resources. One central proposition of this model is that the influence of resource gains is dependent on concurrent resource losses (conceived as stressful): a person with a lack of resources may benefit more in relative terms from gaining resources than a person who already possesses a certain reservoir of resources [23]. Applied to the research questions, it was expected that PSE gains in patients with higher initial distress (parenting hassles and depressive symptoms, respectively) would have a relatively stronger influence on either satisfaction outcome (as compared with patients with a lower initial distress level).

\section{Method}

\subsection{Data Collection}

For the secondary analysis presented here, data from two related research projects sponsored by the German federal health insurance funds [24] [25] were used. In these projects, a comprehensive quality assurance approach including a set of assessments for the areas of PRP (which had not been existent so far) had been developed against the background that PRP institutions (as well as all other rehabilitation clinics) are required by German law to implement external quality assurance measures. Assessments had been developed and evaluated on the levels of structural, process, and outcome quality between September 2007 and August 2008 [25]. On the level of outcome quality, relevant outcome domains (e.g., distress, well-being/resources, functioning, and parenting behavior) and related variables had been specified based on a systematic literature search. Variables had been operationalized using established self-report assessments that were evaluated regarding their psychometric properties and usability in practice. To determine their ability to document differences between PRP facilities in quality-relevant outcome parameters, data had been collected in 45 inpatient PRP centers at two time points (T1: start of inpatient treatment [admission]; T2: end of inpatient treatment [discharge; T1 +3 weeks]). Among the parameters identified as relevant were parenting-related stressors, parenting self-efficacy, depression, and general life satisfaction/satisfaction with health [24]. These variables were used in the secondary analysis.

\subsection{Study Participants}

During data collection, all patients regularly attending a PRP program in one of the participating clinics had been consecutively included (eligibility criteria for the programs as stated above). The selection of hospitals participating in the original projects had been based on several stratification criteria (institution size; geographical region; health insurance provider; indication(s)) to ensure representativeness. The sample size was $n=1799$ (patients participating at both $\mathrm{T} 1$ and $\mathrm{T} 2$; dropout T1-T2: $11.3 \%, \mathrm{n}_{\mathrm{T} 1 \text { only }}=2029$ ). Regarding the small proportion of male patients $(\mathrm{n}=75)$, it was decided not to include these data sets in further analyses so that the effective sample comprised female patients only $(n=1724)$. A regular dropout analysis could not be performed since not all participating clinics had provided reliable data on non-participants. Thus, no definitive statement was possible to what extent participants were representative of the population of PRP patients in general.

\subsection{Instruments}

A subset of questionnaires administered in the original projects was used. Instruments were selected based on theoretical assumptions on the presumed associations of stressors, resources, and subjective health/well-being (see above). To assess PSE, the German version of the parenting self-efficacy subscale of the Parenting Sense of Competence Scale (PSOC) was used (T1; T2) [26] [27]. The subscale consists of seven self-report items assessing subjective parenting competencies showing acceptable internal consistency $(\alpha=0.70$; sample item: "I honestly believe I have all the skills necessary to be a good mother/father to my child"). Parenting hassles were assessed using the German version of the Everyday Stressors Index (ESI; T1) [28] [29], an 18-item questionnaire developed to assess the level of distress caused by parenting hassles in mothers $(\alpha=0.86$; sample item: "Problems with your child(ren)'s behavior"). The nine-item depression module (PHQ-9) of the Patient Health 
Questionnaire PHQ (German version) [30] [31] was used to assess the frequency of depressive symptoms (T1; $\alpha$ $=0.88$; sample item: "Loss of interest or pleasure"). General life satisfaction and satisfaction with health were assessed by means of the Fragen zur Lebenszufriedenheit-Module (FLZ-M), a German-language instrument measuring two dimensions of life satisfaction (T2) [32]. The General Life Satisfaction subscale comprises eight different aspects (e.g., housing; family life). The Satisfaction with Health scale is also composed of eight items (e.g., physical condition/fitness; mobility; $\alpha=0.82$; instruction: "How satisfied are you with....").

\subsection{Statistical Analysis}

Different models were tested that included general life satisfaction vs. satisfaction with health as respective outcomes, parenting hassles, depressive symptoms, and PSE change as predictors. Positive changes in PSE were explored by analyzing changes using average differences of all PSE items (manifest variables) first, followed by analyzing measurement invariance over time by means of a latent change variable that was computed by estimating the mean of the latent difference variable after testing for configural, metric, and scalar invariance [33] [34]. To examine the main and interactive effects of resource gains and stressors on general life satisfaction and satisfaction with health, structural equation modeling (SEM) using MPlus [35] was applied. Models without a latent interaction term (stressor $\mathrm{x}$ resource change) were tested first, followed by models including the interaction term. Latent interactions were specified based on the Latent Moderated Structural Equations (LMS) procedure proposed by Klein and Moosbrugger [36] which is implemented as an analysis feature in MPlus. The Akaike Information Criterion (AIC) was chosen as an index of relative model fit of the model with an additional

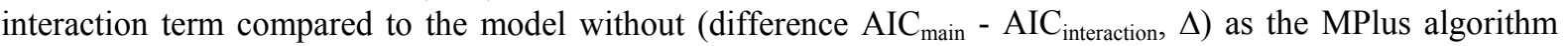
used for latent interaction analysis does not provide other model fit indices. According to Burnham and Anderson [37], differences in AIC values for two measurement models $<2$ indicate an acceptable relative fit. The effects of the interaction term are given as unstandardized path coefficients since the MPlus algorithm used does not provide standardized coefficients. Analyses on a construct level were conducted using the Full Information Maximum Likelihood (FIML) algorithm [38]. Multiple imputations were applied for missing data in specific items using SPSS 18.

\subsection{Ethical Considerations}

The patients participating in the original projects had given their informed consent for participation in compliance with the Helsinki declaration. Data had been collected in the context of routine quality assurance by the German health insurance funds; the appropriate data protection rules had been applied.

\section{Results}

\subsection{Sample Characteristics}

Patients had an average age of 37 years, with the majority being treated because of psychosomatic symptoms, were predominantly married (or living in a partnership), and were mostly employed (Table 1).

The average number of children attending the PRP program together with their mother (i.e., for whom a questionnaire with child data (data not presented here) was existent) was $1.24(\mathrm{SD}=0.78)$. The number of children as such had not been assessed in the original projects.

\subsection{Changes in Self-Efficacy}

It was first analyzed whether there was a positive change in PSE in the course of PRP (using the average differences of all PSE items). This was confirmed $\left(\mathrm{M}_{\mathrm{T} 1}=3.13(\mathrm{SD}=0.79) ; \mathrm{M}_{\mathrm{T} 2}=3.43(\mathrm{SD}=0.75) ; \mathrm{t}(\mathrm{df})=-19.718\right.$ (1616), $\mathrm{p}<0.01 ; \mathrm{d}=0.39)$. A significant change in PSE could be corroborated as the estimated mean of the latent change variable was positive and significantly different from zero $(\mathrm{M}=0.27 ; \mathrm{p}<0.01)$, indicating that there was a significant (albeit small) gain in PSE.

\subsection{Parenting Hassles, Resource Change and Satisfaction}

After exploratory factor analysis (EFA; principal component analysis without rotation) did not yield a unidimensional structure of the general life satisfaction (GLS) subscale items, three different GLS models based on 
Table 1. Sample characteristics ${ }^{\mathrm{a}}$.

\begin{tabular}{|c|c|c|c|c|c|}
\hline $\mathbf{N}$ & $1724^{\mathrm{a}}$ & & & & \\
\hline Age in years, $M(S D)$ & $37.4(7.66)$ & & & & \\
\hline Medical condition & $\mathbf{n}$ & $\%$ & Employment status & $\mathbf{n}$ & $\%$ \\
\hline Psychosomatic disorders & 858 & 53.7 & Fulltime & 312 & 18.5 \\
\hline Rheumatologic disorders & 454 & 28.4 & Halftime or less & 613 & 48.2 \\
\hline Respiratory system disorders & 78 & 4.9 & Housewife & 364 & 21.6 \\
\hline Psychiatric disorders & 64 & 4.0 & Vocational training & 8 & 0.5 \\
\hline Metabolic disorders & 52 & 3.0 & Unemployed & 97 & 5.7 \\
\hline Cardiovascular disorders & 36 & 2.3 & Disability insurance benefit & 10 & 0.6 \\
\hline Other & 57 & 3.6 & Retirement pension & 27 & 1.6 \\
\hline Not stated & 125 & 7.3 & Other & 56 & 3.3 \\
\hline Marital status & $\mathbf{n}$ & $\%$ & Not stated & 37 & 2.1 \\
\hline Single & 273 & 16.1 & Occupational position & $\mathbf{n}$ & $\%$ \\
\hline Married & 1045 & 61.6 & Worker & 207 & 12.7 \\
\hline Divorced/separated & 322 & 19.0 & Employee & 1161 & 71.2 \\
\hline Widowed & 57 & 3.4 & Self-employed & 89 & 5.5 \\
\hline Not stated & 27 & 1.6 & Civil servant & 75 & 4.6 \\
\hline Living in partnership & $\mathbf{n}$ & $\%$ & Other & 98 & 6.0 \\
\hline Yes & 1200 & 71.6 & Not stated & 94 & 5.5 \\
\hline No & 476 & 28.4 & Social class ${ }^{b}$ & $\mathbf{n}$ & $\%$ \\
\hline \multirow[t]{4}{*}{ Not stated } & 48 & 2.8 & Lower & 72 & 4.6 \\
\hline & & & Middle & 1083 & 62.6 \\
\hline & & & Higher & 416 & 26.4 \\
\hline & & & Not stated & 153 & 8.9 \\
\hline
\end{tabular}

andicated numbers refer to valid percents except for "not stated" (which refers to the overall sample); ${ }^{\mathrm{b}}$ Social class membership was computed using a social class index that uses the variables "highest level of education", "employment status" and "household income". Aggregated scores indicate social class affiliation (lower, middle, and higher class) depending on their value.

subsequent oblique rotation EFAs were each used measuring different but partially overlapping aspects of GLS (model 1: social and financial living conditions [items: friends; hobbies; income]; model 2: financial and healthrelated living conditions [items: income; occupation; health; housing/living conditions]; model 3: social living environment [items: housing/living conditions; family life; partnership/sexuality]).

As shown in Figure 1, parenting hassles were negatively associated with each of the GLS facets while the positive path from resource change to GLS was always low to negligible. The highest proportion of explained variance in the overall model was found for model 3. For each GLS facet, overall model fits were satisfactory. Models including an additional latent interaction variable (parenting hassles $\times$ resource change) revealed no significant interaction between the two predictors (Figure 1).

Using satisfaction with health as the outcome in a model that comprised parenting hassles and resource change as predictors without the interaction of both $\left(\chi^{2}=103.390[\mathrm{df}=48 ; \mathrm{p}=0.000]\right.$; CFI $=0.988$; TLI $=0.983$; RMSEA $=0.026[0.019 ; 0.033]$; SRMR $=0.025 ; \mathrm{n}=1721)$, there was a small negative association of parenting hassles and satisfaction $(\beta=-0.22 ; \mathrm{p}<0.01)$ while there was a small positive path coefficient for resource change $(\beta=0.12 ; \mathrm{p}<0.01)$. Both predictors were weakly associated $(\mathrm{r}=0.17, \mathrm{p}<0.01)$. The proportion of variance explained in the outcome was rather small $\left(\mathrm{R}^{2}=0.05\right)$. A model including an additional latent interaction term $\left(\mathrm{AIC}_{\text {main }}=50570.399 ; \mathrm{AIC}_{\text {interaction }}=50571.890 ; \Delta=1.491\right)$ did not show a significant interaction $(\mathrm{b}=0.06$; $\mathrm{p}=0.58)$. 


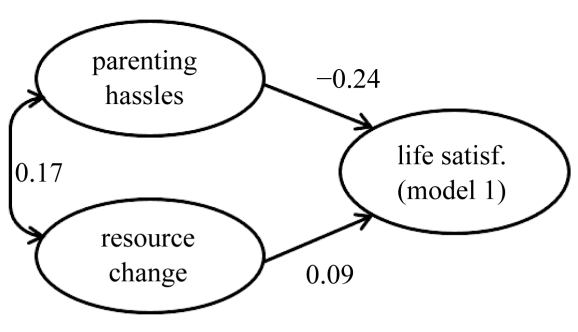

(a) Model 1, main effects model; $\chi^{2}=61.605$ $[\mathrm{df}=39 ; \mathrm{p}=0.012] ; \mathrm{CFI}=0.991 ; \mathrm{TLI}=0.988$; RMSEA $=0.018$ [0.009; 0.027]; SRMR $=0.022$; $\mathrm{n}=1720 ; \mathrm{R}^{2}=0.06$

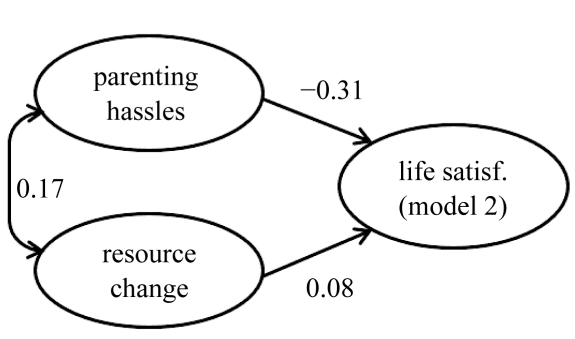

(b) Model 2, main effects model; $\chi^{2}=60.622$ $[\mathrm{df}=49 ; \mathrm{p}=0.123]$; $\mathrm{CFI}=0.996 ; \mathrm{TLI}=0.995$; RMSEA $=0.012$ [0.000; 0.021]; SRMR $=0.019$; $\mathrm{n}=1720 ; \mathrm{R}^{2}=0.09$

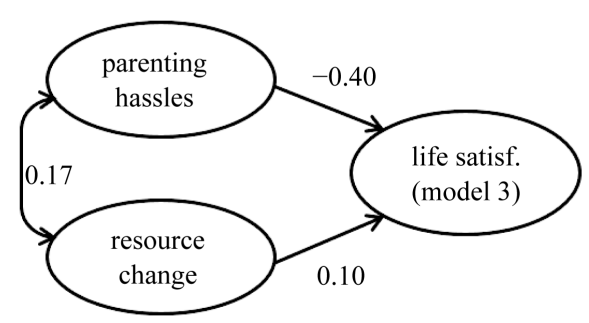

(c) Model 3, main effects model; $\chi^{2}=73.875$ $[\mathrm{df}=39 ; \mathrm{p}=0.001] ; \mathrm{CFI}=0.986 ; \mathrm{TLI}=0.981$; RMSEA $=0.023[0.015 ; 0.031]$; SRMR $=0.023$; $\mathrm{n}=1719 ; \mathrm{R}^{2}=0.16$

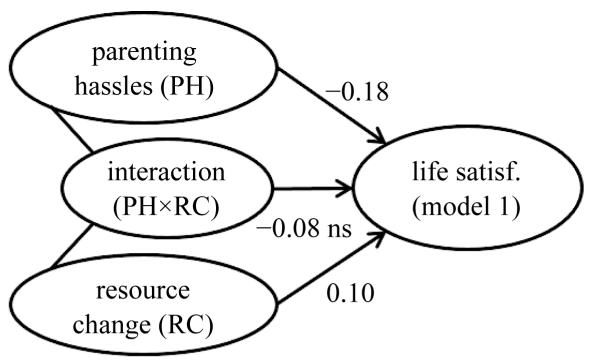

(a) Model 1, interaction model; relative model fit: AIC diff $=0.244$

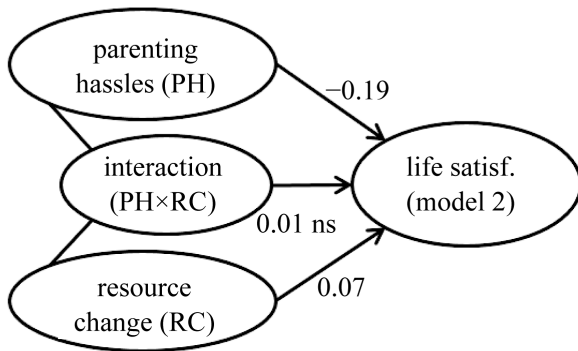

(b) Model 2, interaction model; relative model fit: AIC diff $=1.991$

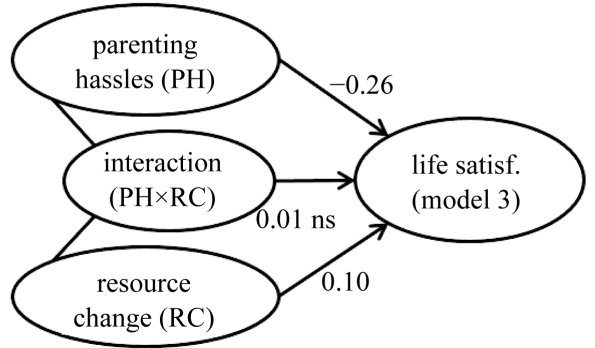

(c) Model 3, interaction model; relative model fit: AIC diff $=2.0$

Figure 1. Effects of parenting hassles and resource change on general life satisfaction ${ }^{\mathrm{a}}$. ${ }^{\mathrm{a}}$ Note: main effect models are shown in the left section of the figure, models with additional interaction term in the right section; (a) Model 1 (social and financial living conditions); (b) Model 2 (financial and health-related living conditions); (c) Model 3 (social living environment). All coefficients $=p<0.05$, unless otherwise stated; relative model fit of the model with an additional interaction term: difference $\mathrm{AIC}_{\text {main }}-\mathrm{AIC}_{\text {interaction}}$; for interaction models, unstandardized coefficients are shown. $\mathrm{PH}=$ parenting hassles; $\mathrm{RC}=$ resource change.

Taken together, the analyses showed that parenting hassles at $\mathrm{T} 1$ were negatively associated with satisfaction at T2 while resource gains had a weak positive association with satisfaction. A hypothesized interactive effect of resource change and parenting hassles on satisfaction was not documented.

\subsection{Depression, Resource Change and Satisfaction}

Depressive symptoms at the beginning of treatment were negatively associated with general life satisfaction $(G L S)$ in all models. Resource change was not significantly associated with satisfaction (except from a negligi- 
ble positive effect in model 1; Figure 2). In models including an additional latent interaction (depressive symptoms $\mathrm{x}$ resource change), no significant path was found for the interaction term of both predictors in any of the models. Depressive symptoms and resource change were not significantly correlated (Figure 2).

In a model with satisfaction with health as the outcome $\left(\chi^{2}=305.038[\mathrm{df}=83 ; \mathrm{p}=0.000]\right.$; $\mathrm{CFI}=0.968$; TLI $=$ $0.959 ;$ RMSEA $=0.039$ [0.035; 0.044]; $\left.\mathrm{SRMR}=0.038 ; \mathrm{n}=1720 ; \mathrm{R}^{2}=0.19\right)$, a negative association was found for depressive symptoms $(\beta=-0.43 ; \mathrm{p}<0.01)$ while there was a weak positive association of resource change and satisfaction $(\beta=0.11 ; \mathrm{p}<0.01)$. There was no significant correlation between the two variables $(\mathrm{r}=0.07 ; \mathrm{p}=0.08)$.

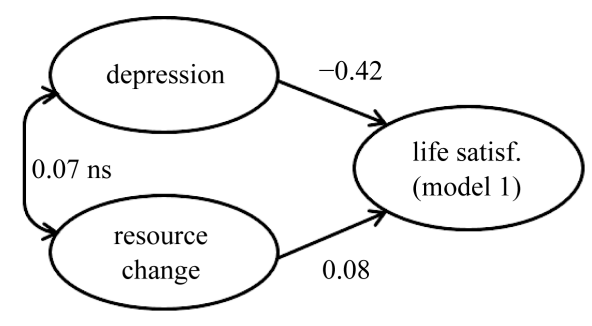

(a) Model 1, main effects model; $\chi^{2}=220.656$ $[\mathrm{df}=71 ; \mathrm{p}=0.000] ; \mathrm{CFI}=0.970 ; \mathrm{TLI}=0.962$; RMSEA $=0.035$ [0.030; 0.040]; SRMR $=0.031$; $\underline{\mathrm{n}=1719 ; \mathrm{R}^{2}=0.18}$

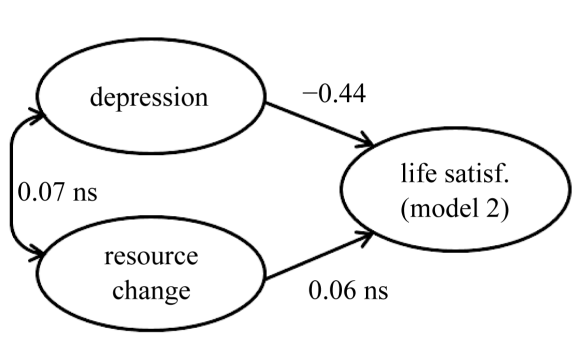

(b) Model 2, main effects model; $\chi^{2}=233.890$ $[\mathrm{df}=84 ; \mathrm{p}=0.000]$; $\mathrm{CFI}=0.972 ; \mathrm{TLI}=0.966$; RMSEA $=0.032$ [0.027; 0.037]; SRMR $=0.029$; $\underline{\mathrm{n}}=1719 ; \mathrm{R}^{2}=0.19$

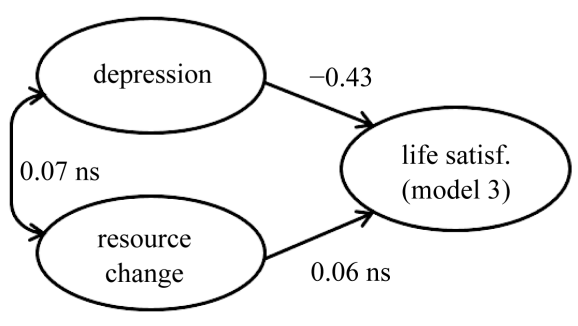

(c) Model 3, main effects model; $\chi^{2}=166.562$ $[\mathrm{df}=71 ; \mathrm{p}=0.000]$; $\mathrm{CFI}=0.980 ; \mathrm{TLI}=0.975$; RMSEA $=0.028[0.022 ; 0.034]$; SRMR $=0.025$; $\mathrm{n}=1719 ; \mathrm{R}^{2}=0.19$

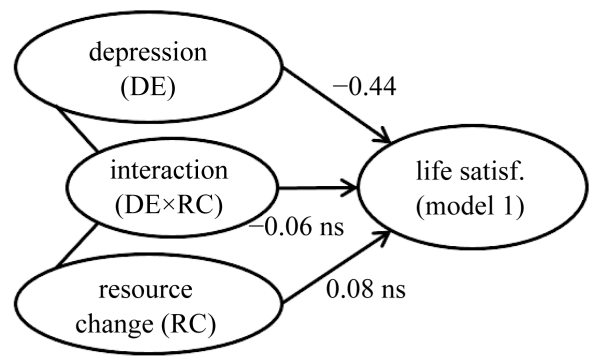

(a) Model 1, interaction model; relative model fit: AIC diff $=1.393$

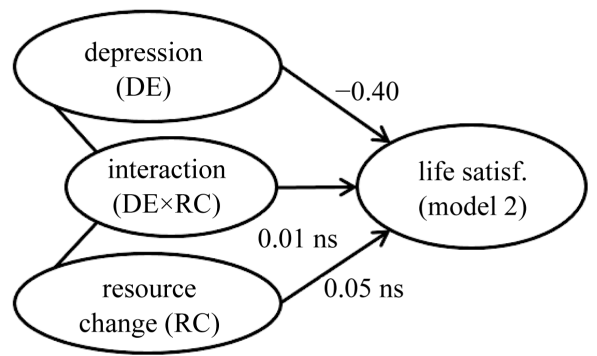

(b) Model 2, interaction model; relative model fit: AIC diff $=0.344$

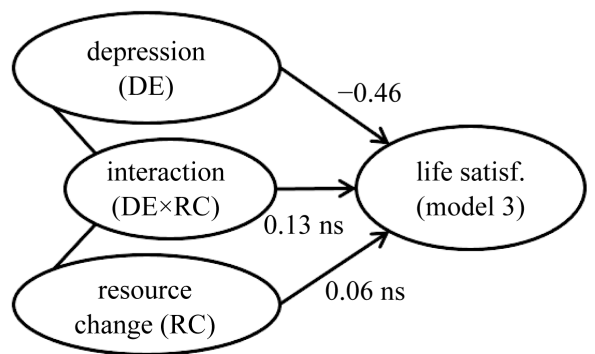

(c) Model 3, interaction model; relative model fit: AIC diff $=0.973$

Figure 2. Effects of depression and resource change on general life satisfaction ${ }^{\mathrm{a}}$. ${ }^{\mathrm{a}}$ Note: main effect models are shown in the left section of the figure, models with additional interaction term in the right section; (a) Model 1 (social and financial living conditions); (b) Model 2 (financial and health-related living conditions); (c) Model 3 (social living environment). All coefficients $=p<0.05$, unless otherwise stated; relative model fit of the model with an additional interaction term: difference $\mathrm{AIC}_{\text {main }}-\mathrm{AIC}_{\text {interaction }}$; for interaction models, unstandardized coefficients are shown. $\mathrm{DE}=$ depression; $\mathrm{RC}=$ resource change. 
A model including an additional latent interaction of depression and resource change $\left(\mathrm{AIC}_{\text {main }}=61466.230\right.$; $\mathrm{AI}-$ $\left.\mathrm{C}_{\text {interaction }}=61465.196 ; \Delta=1.034\right)$ did not reveal a significant interaction $(\mathrm{b}=0.17 ; \mathrm{p}=0.14)$.

Taken together, the different facets of life satisfaction at T2 were each negatively associated with the presence of depressive symptoms at T1. Depression also showed a negative association with subjective health while resource gains influenced satisfaction only marginally. Again, the data did not support an interactive influence of resource change and depressive symptoms on the satisfaction measures.

\section{Discussion}

In this secondary analysis of quality assurance data collected in the context of an inpatient rehabilitation or prevention program for parents (PRP), significant negative associations of both parenting hassles and depressive symptoms assessed at the start of treatment with mothers' satisfaction at discharge were found. An increase in parenting self-efficacy was associated only weakly with general life satisfaction and satisfaction with health. The associations of self-efficacy gains with satisfaction were not moderated by the baseline stress level.

The finding that parenting hassles experienced at the start of a PRP measure were negatively correlated with satisfaction independent of the small positive effect of resource gains suggests that these problems continue to impair patients' well-being despite increased subjective competencies to deal with parenting demands. It is possible that a regular treatment duration of three weeks will not be sufficient to reduce patients' distress noticeably (that may have built up over a long period). Participating in an inpatient PRP program also implies being outside the common daily routine and, for some patients, spending several weeks in a rehabilitation center without their children. Thus, they may not have been able to gain a realistic impression of how to organize their own future everyday life or adopt their new skills in problem situations.

The findings that depressive symptoms were associated with reduced satisfaction at the end of treatment lend support to other research showing that depressive mood and symptoms are among the most frequent diagnoses in PRP patients [13]. The PHQ scale mean $\left(\mathrm{M}_{\mathrm{T1}}=11.29, \mathrm{SD}=5.37\right)$ indicates a considerable initial depressive burden in this sample of mothers (in terms of a moderate severity of depression [30]). Moreover, findings that depression can impair marital/relationship satisfaction in mothers [39] [40] correspond to the results from this study; the general life satisfaction model depicting satisfaction with close family and partner relationships (model 3) showed the highest proportion of outcome variance explained by depression (and parenting hassles).

A positive change in parenting self-efficacy in the course of PRP was documented which was rather small; the associations of gains with the satisfaction measures were also rather weak and inconsistent. Generally, selfefficacy gains may imply an increase in mastery with regard to creating adequate living conditions in the domain of parenting/child care, and evidence from other studies shows that parenting self-efficacy is associated with subjective well-being and higher satisfaction with family and spouse/partner [41]-[43]. Our findings must, however, be interpreted with caution. Whether the PRP program had any effects in terms of self-efficacy gains can only be determined in an intervention study using a control group design. Both the original quality assurance projects and this secondary analysis lacked both a control condition and a design aimed at evaluating program efficacy, given their different research focus. Moreover, the time interval of 3 weeks between T1 and T2 is rather short. This raises the question whether self-efficacy gains should be regarded as meaningful positive change or rather reflect some kind of measurement error. This question can also be answered within the framework of an intervention study only.

No interaction of self-efficacy gains and baseline stressors was found contrary to the assumptions based on COR theory (and in contrast to evidence that highly distressed mothers may benefit less from parent-specific interventions [44]). This may be at least partly due to the operationalization of the constructs examined. Conceptually, the question is whether stressors should be operationalized as proxy measures of resource losses (a term used in COR theory). To what extent the distress experienced by patients constitutes a consequence or end point of losses in resources is speculative since changes in resources or life circumstances over time prior to PRP (i.e., a "longitudinal" process) had not been assessed in the original projects.

In terms of methodology, the LMS approach used for modelling the latent interaction seems reasonable since it has generated results in simulation studies that are on a par with other approaches. However, a state of the art procedure is yet to be established as the modelling of latent interactions in the context of SEM is relatively new and performed rather infrequently.

Several limitations of this study should be discussed. First, as mentioned above, the correlational design of 
this analysis does not allow a statement as to whether there is an effect of PRP programs on patients' subjective competencies or well-being. The combined use of cross-sectional (stressors, satisfaction) and "longitudinal" (changes in parenting self-efficacy) data in the models should be viewed critically, as well as the lack of T2 data for the stressor variables. To what extent the distress experienced by patients constitutes a consequence or end point of losses in psychosocial resources is speculative since changes in resources or life circumstances over time prior to PRP (i.e., a "longitudinal" process) had not been assessed in the original projects. These issues also reflect the fact that the original data were collected in projects that had a different focus; thus, there is no "perfect fit" regarding the objective of this secondary analysis.

Moreover, the lack of reliable data from several participating institutions concerning dropouts must be regarded as a drawback pertaining to the question of representativeness of study participants. The issue of common method variance is also critical and should be kept in mind when interpreting the study results given that all data are based on self-report.

Finally, in light of the small number of fathers participating in the original projects and their exclusion in this secondary analysis, no statement could be made as to whether the associations of the variables examined may vary by gender and which implications may be derived for designing health care interventions for fathers [45].

\section{Conclusion}

In consideration of the limitations stated above, implications of the secondary analysis that go beyond the specifics of a particular health care setting refer to how distress experienced by mothers/fathers can be addressed in interventions for parents. Reducing parental distress (in its various definitions/operationalizations) is a goal in diverse parent trainings and interventions [45]. It seems useful to specify prevalent stressors of the respective target group (e.g., mothers with mental health problems, and mothers with a chronically ill child) and to design treatment modules or programs that focus on these stressors. In intervention studies, their relevance as factors influencing treatment efficacy (e.g., as moderating variables [44] [46]) should be evaluated. In quality management and quality assurance, they may be included, for instance, in comparative analyses across rehabilitation facilities [24]. Throughout, an important point to be given consideration is the potential specifics of fathers as compared with mothers in programs directed at distressed parents (e.g., in terms of prevalent stressors or treatment efficaciousness).

\section{Author Statements}

No conflicting interests to disclose.

This publication was funded by the German Research Foundation (DFG) and the University of Würzburg in the funding program Open Access Publishing.

\section{References}

[1] Byron, K. (2005) A Meta-Analytic Review of Work-Family Conflict and Its Antecedents. Journal of Vocational Behavior, 67, 169-198. http://dx.doi.org/10.1016/j.jvb.2004.08.009

[2] Franz, M., Lensche, H. and Schmitz, N. (2003) Psychological Distress and Socioeconomic Status in Single Mothers and Their Children in a German City. Social Psychiatry and Psychiatric Epidemiology, 38, 59-68. http://dx.doi.org/10.1007/s00127-003-0605-8

[3] Sällfors, K. and Hallberg, L. (2003) A Parental Perspective on Living with a Chronically Ill Child: A Qualitative Study. Families, Systems, \& Health, 21, 193-204. http://dx.doi.org/10.1037/1091-7527.21.2.193

[4] Crnic, K.A., Gaze, C. and Hoffman, C. (2005). Cumulative Parenting Stress across the Preschool Period: Relations to Maternal Parenting and Child Behaviour at Age 5. Infant and Child Development, 14, 117-132. http://dx.doi.org/10.1002/icd.384

[5] Östberg, M., Hagekull, B. and Hagelin, E. (2007) Stability and Prediction of Parenting Stress. Infant and Child Development, 16, 207-223. http://dx.doi.org/10.1002/icd.516

[6] Skreden, M., Skari, H., Malt, U.F., Pripp, A.H., Björk, M.D., Faugli, A. and Emblem, R. (2012) Parenting Stress and Emotional Wellbeing in Mothers and Fathers of Preschool Children. Scandinavian Journal of Public Health, 40, 596604. http://dx.doi.org/10.1177/1403494812460347

[7] Sperlich, S., Peter, R. and Geyer, S. (2012) Applying the Effort-Reward Imbalance Model to Household and Family Work: a Population-Based Study of German Mothers. BMC Public Health, 12, 12. 
http://dx.doi.org/10.1186/1471-2458-12-12

[8] Tao, W., Janzen, B.L. and Abonyi, S. (2010) Gender, Division of Unpaid Family Work and Psychological Distress in Dual-Earner Families. Clinical Practice and Epidemiology in Mental Health, 6, 36-46. http://benthamopen.com/FULLTEXT/CPEMH-6-36

[9] Civic, D. and Holt, V.L. (2002) Maternal Depressive Symptoms and Child Behaviour Problems in a Nationally Representative Normal Birthweight Sample. Maternal and Child Health Journal, 4, 215-221.

[10] Herwig, J.E. and Bengel, J. (2005) Schweregrad und Störungswert der Belastungen von Frauen in Mutter-KindMaßnahmen [Severity and Relevance of Distress in Women Attending a Mother-Child Treatment Program]. Zeitschrift für Klinische Psychologie Psychiatrie und Psychotherapie, 53, 1-15.

[11] Mazur, E. (2006) Biased Appraisals of Parenting Daily Hassles among Mothers of Young Children: Predictors of Parenting Adjustment. Cognitive Therapy and Research, 30, 161-175. http://dx.doi.org/10.1007/s10608-006-9031-Z

[12] Mistry, R., Stevens, G.D., Sareen, H., De Vogli, R. and Halfon, N. (2007) Parenting-Related Stressors and Self-Reported Mental Health of Mothers with Young Children. American Journal of Public Health, 97, 1261-1268. http://dx.doi.org/10.2105/AJPH.2006.088161

[13] Arnhold-Kerri, S., Sperlich, S. and Collatz, J. (2003) Krankheitsprofile und Therapieeffekte von Patientinnen in Mutter-Kind-Einrichtungen [Disease Profiles and Therapy Effects of Patients in Mother-Child Rehabilitation Centres]. Rehabilitation, 42, 290-300. http://dx.doi.org/10.1055/s-2003-42858

[14] Fassmann, H., Grüninger, M., Schneider, A.H. and Steger, R. (2008) Bedarfs- und Bestandsanalyse von Vorsorge- und Rehabilitationsmaßnahmen für Mütter und Väter in Einrichtungen des Deutschen Müttergenesungswerks. Projektabschlussbericht. Materialien aus dem Institut für empirische Soziologie an der Friedrich-Alexander-Universität ErlangenNürnberg [Demand and Status Analysis of Rehabilitation and Prevention Measures for Mothers and Fathers in Institutions of the Muettergenesungswerk (Mothers' Convalescence and Recuperation Scheme)]. Project Report, Friedrich Alexander University at Erlangen and Nuremberg.

[15] Vogel, H. and Zdrahal-Urbanek, J. (2004) Rehabilitation in Germany: New Challenges of a Structured Social Security Scheme. International Journal of Rehabilitation Research, 27, 93-98. http://dx.doi.org/10.1097/01.mrr.0000128058.46440.d0

[16] De Montigny, F. and Lacharité, C. (2005) Perceived Parental Efficacy: Concept Analysis. Journal of Advanced Nursing, 49, 387-396. http://dx.doi.org/10.1111/j.1365-2648.2004.03302.x

[17] Bloomfield, L. and Kendall, S. (2012) Parenting Self-Efficacy, Parenting Stress and Child Behaviour before and after a Parenting Programme. Primary Health Care Research and Development, 13, 364-372. http://dx.doi.org/10.1017/S1463423612000060

[18] Farris, J.R., Carothers Bert, S.S., Nicholson, J.S., Glass, K. and Borkowski, J.G. (2013) Effective Intervention Programming: Improving Maternal Adjustment through Parent Education. Administration and Policy in Mental Health and Mental Health Services Research, 40, 211-223. http://dx.doi.org/10.1007/s10488-011-0397-1

[19] Lindsay, G., Strand, S. and Davis, H. (2011) A Comparison of the Effectiveness of Three Parenting Programmes in Improving Parenting Skills, Parent Mental Well-Being and Children's Behaviour When Implemented on a Large Scale in Community Settings in 18 English Local Authorities: The Parenting Early Intervention Pathfinder (PEIP). BMC Public Health, 11, 962. http://dx.doi.org/10.1186/1471-2458-11-962

[20] Salonen, A.H., Kaunonen, M., Astedt-Kurki, P., Järvenpää, A.L., Isoaho, H. and Tarkka, M.T. (2011) Effectiveness of an Internet-Based Intervention Enhancing Finnish Parents' Parenting Satisfaction and Parenting Self-Efficacy during the Postpartum Period. Midwifery, 27, 832-841. http://dx.doi.org/10.1016/j.midw.2010.08.010

[21] Katholische Arbeitsgemeinschaft für Müttergenesung KAG [Catholic Working Group on Maternal Health] (2012) Rahmenkonzept zur stationären Vorsorge und Rehabilitation für Mütter, Mutter/Kind und Vater/Kind, überarbeitete Fassung 2012 [Conceptual Framework for Inpatient Prevention and Rehabilitation of Mothers, Mothers with Children and Fathers with Children. Revised Version 2012]. KAG, Freiburg.

[22] Hobfoll, S.E. (1989) Conservation of Resources: A New Attempt at Conceptualizing Stress. American Psychologist, 44, 513-524. http://dx.doi.org/10.1037/0003-066X.44.3.513

[23] Wells, J.D., Hobfoll, S.E. and Lavin, J. (1999) When It Rains, It Pours: The Greater Impact of Resource Loss Compared to Gain on Psychological Distress. Personality and Social Psychology Bulletin, 25, 1172-1182. http://dx.doi.org/10.1177/01461672992512010

[24] Lukasczik, M., Gerlich, C., Musekamp, G., Saupe-Heide, M., Löbmann, R., Vogel, H. and Neuderth, S. (2014) Externe Qualitätssicherung in Einrichtungen der stationären Vorsorge und Rehabilitation für Mütter und Väter einschließlich Mutter-/Vater-Kind-Einrichtungen: Einrichtungsvergleichende Analysen im Bereich Ergebnisqualität [External Quality Assurance in Inpatient Prevention and Rehabilitation Centers for Mothers, Fathers and Children: Comparative Outcome Quality Analyses across Rehabilitation/Prevention Centers]. Gesundheitswesen, 76, 56-64. 
http://dx.doi.org/10.1055/s-0033-1337994

[25] Neuderth, S., Lukasczik, M., Musekamp, G., Gerlich, C., Saupe-Heide, M., Löbmann, R. and Vogel, H. (2013) Entwicklung von Verfahrensweisen und Instrumenten zur externen Qualitätssicherung in Einrichtungen der stationären Vorsorge und Rehabilitation für Mütter und Väter einschließlich Mutter-/Vater-Kind-Einrichtungen [Development of Procedures and Instruments for External Quality Assurance in Inpatient Rehabilitation and Prevention Centers for Mothers, Fathers and Children]. Rehabilitation, 52, 10-19. http://dx.doi.org/10.1055/s-0032-1323650

[26] Johnston, C. and Mash, E.J. (1989) A Measure of Parenting Satisfaction and Efficacy. Journal of Clinical Child Psychology, 18, 167-175. http://dx.doi.org/10.1207/s15374424jccp1802_8

[27] Miller, Y. (2001) Erziehung von Kindern im Kindergartenalter: Erziehungsverhalten und Kompetenzüberzeugungen von Eltern und der Zusammenhang zu kindlichen Verhaltensstörungen [Parenting of Kindergarten-Aged Children: Parenting Behavior, Parental Self-Efficacy and Their Relation to Child Behavior Problems]. Dissertation, Technical University of Braunschweig, Braunschweig.

[28] Hall, L.A. (1990) Prevalence and Correlates of Depressive Symptoms in Mothers of Young Children. Public Health Nursing, 7, 71-79. http://dx.doi.org/10.1111/j.1525-1446.1990.tb00615.x

[29] Jäkel, J. and Leyendecker, B. (2008) Tägliche Stressfaktoren und Lebenszufriedenheit türkischstämmiger Mütter in Deutschland [Everyday Stressors and Life Satisfaction of Mothers of Turkishorigin in Germany]. Zeitschrift für Gesundheitspsychologie, 16, 12-21. http://dx.doi.org/10.1026/0943-8149.16.1.12

[30] Kroenke, K., Spitzer, R.L. and Williams, J.B. (2001) The PHQ-9: Validity of a Brief Depression Severity Measure. Journal of General Internal Medicine, 16, 606-613. http://dx.doi.org/10.1046/j.1525-1497.2001.016009606.x

[31] Löwe, B., Spitzer, R.L., Zipfel, S. and Herzog, W. (2002) PHQ-D. Manual, Komplettversion und Kurzform [Patient Health Questionnaire, German Version. Manual, Full Version and Short Version]. https://www.klinikum.uni-heidelberg.de/fileadmin/medizinische_klinik/Abteilung_2/pdf/Komplett_PHQ_Fragebogen. pdf

[32] Henrich, G. and Herschbach, P. (2000) Questions on Life Satisfaction (FLZM)—A Short Questionnaire for Assessing Subjective Quality of Life. European Journal of Psychological Assessment, 16, 150-159. http://dx.doi.org/10.1027//1015-5759.16.3.150

[33] McArdle, J.J. and Hamagami, F. (2001) Latent Difference Score Structural Models for Linear Dynamic Analysis with Incomplete Longitudinal Data. In: Collins, L.M. and Sayer, A.G., Eds., New Methods for the Analysis of Change, American Psychological Association, Washington DC, 139-175.

[34] Schuler, M. and Jelitte, M. (2012) Messen wir bei allen Personen das Gleiche? Zur Invarianz von Messungen und Response Shift in der Rehabilitation-Teil 1 [Do We Measure the Same in All Persons? On Measurement Invariance and Response Shift in Rehabilitation Research, Part 1]. Rehabilitation, 51, 332-339. http://dx.doi.org/10.1055/s-0031-1291313

[35] Muthén, L.K. and Muthén, B.O. (2007) MPlus User’s Guide. 5th Edition, Muthén \& Muthén, Los Angeles.

[36] Klein, A. and Moosbrugger, H. (2000) Maximum Likelihood Estimation of Latent Interaction Effects with the LMS Method. Psychometrika, 65, 457-474. http://dx.doi.org/10.1007/BF02296338

[37] Burnham, K.P. and Anderson, D.R. (2002) Model Selection and Multimodel Inference: A Practical InformationTheoretic Approach. Springer, New York.

[38] Enders, C.K. (2010) Applied Missing Data Analysis. Guilford, New York.

[39] Herwig, J.E., Wirtz, M. and Bengel, J. (2004) Depression, Partnership, Social Support, and Parenting: Interaction of Marital Factors with Behavioral Problems of the Child. Journal of Affective Disorders, 80, 199-208. http://dx.doi.org/10.1016/S0165-0327(03)00112-5

[40] Holt-Lunstad, J., Birmingham, W. and Jones, B.Q. (2008) Is There Something Unique about Marriage? The Relative Impact of Marital Status, Relationship Quality, and Network Social Support on Ambulatory Blood Pressure and Mental Health. Annals of Behavioral Medicine, 35, 239-244. http://dx.doi.org/10.1007/s12160-008-9018-y

[41] Haslam, D.M., Pakenham, K.I. and Smith, A. (2006) Social Support and Postpartum Depressive Symptomatology: The Mediating Role of Maternal Self-Efficacy. Infant Mental Health Journal, 27, 276-291. http://dx.doi.org/10.1002/imhj.20092

[42] Howell, E.A., Mora, P.A., DiBonaventura, M.D. and Leventhal, H. (2009) Modifiable Factors Associated with Changes in Postpartum Depressive Symptoms. Archives of Women's Mental Health, 12, 113-120. http://dx.doi.org/10.1007/s00737-009-0056-7

[43] Sevigny, P.R. and Loutzenhiser, L. (2010) Predictors of Parenting Self-Efficacy in Mothers and Fathers of Toddlers. Child: Care, Health and Development, 36, 179-189. http://dx.doi.org/10.1111/j.1365-2214.2009.00980.x

[44] Smith, K.E., Landry, S.H. and Swank, P.R. (2005) The Influence of Decreased Parental Resources on the Efficacy of a 
Responsive Parenting Intervention. Journal of Consulting and Clinical Psychology, 73, 711-720. http://dx.doi.org/10.1037/0022-006X.73.4.711

[45] Barlow, J., Smailagic, N., Huband, N., Roloff, V. and Bennett, C. (2014) Group-Based Parent Training Programmes for Improving Parental Psychosocial Health. Cochrane Database of Systematic Reviews, 6, CD002020. http://dx.doi.org/10.1002/14651858.CD002020.pub4

[46] Muzik, M., Rosenblum, K.L., Alfafara, E.A., Schuster, M.M., Miller, N.M., Waddell, R.M. and Kohler, E.S. (2015) Mom Power: Preliminary Outcomes of a Group Intervention to Improve Mental Health and Parenting among HighRisk Mothers. Archives of Women's Mental Health, Epub Ahead of Print. http://dx.doi.org/10.1007/s00737-014-0490-z 